\title{
Impact of litigation on senior clinicians: implications for risk management
}

Clinical Risk Unit, Directorate of Public Health, North Thames Region, 40 Eastbourne Terrace, London W2

3QR

Pippa Bark, senior

research fellow

Charles Vincent, senior

lecturer

Laura Olivieri, research

assistant

Angela Jones, formerly

consultant in public

health medicine

Clinical Risk Unit,

Psychology

Department

(Torrington Place),

University College,

Gower Street, London

WC1E 6BT

Pippa Bark, senior

research fellow

Charles Vincent, senior

lecturer

Correspondence to:

Ms P Bark, Clinical Risk

Unit, Directorate of Public

Health, North Thames

Region, 40 Eastbourne

Terrace, London W2 3QR.

Accepted for publication

14 January 1997

\begin{abstract}
Objectives-To investigate the impact of litigation on consultants and senior registrars and to establish their views on methods of reducing adverse events and litigation.

Design-Postal survey.

Setting-Acute hospitals in the North Thames (West) Regional Health Authority.

Subjects-1011 consultants and senior registrars in acute hospitals.

Main measures-Perceived causes and effects of adverse events; views on methods of reducing litigation and adverse events

Results-769 (76\%) doctors responded. $288(37 \%)$ had been involved in litigation at some point during their career; 213 surgeons (49\%) and $75(23 \%)$ doctors in the medical specialties. Anger, distress, and feeling personally attacked were common responses to litigation. Clinicians' views on reducing litigation emphasised the need for change at the clinical level. Supervision of junior staff, workload, and training in communication skills were to the fore.
\end{abstract}

Conclusions-The high frequency of doctors who have experienced litigation and the emotional responses described indicate that clinicians require support at several levels. At a personal level, support can be offered to clinicians going through the litigation process or after an adverse event. Also, managerial support is needed by offering financial and practical help in correcting the factors that have been consistently identified as producing high risk situations to minimise the possibility of a reoccurrence. Accidents in medicine are, by their very nature, costly in human and financial terms and the root causes must be tackled. Recommendations are made for clinicians and risk management teams.

(Quality in Health Care 1997;6:7-13)

Keywords: litigation; risk management.

\section{Introduction}

Current estimates of annual expenditure in the United Kingdom on settlements of medical negligence claims and legal costs are approaching $£ 150 \mathrm{~m}$ a year. ${ }^{1}$ In high risk specialities, such as obstetrics, general surgery, accident and emergency, and orthopaedics, litigation has increased sharply in recent years. As hospital trusts now bear the financial losses associated with litigation, albeit with the assistance of the Central Negligence Scheme for Trusts, the body set up to insure hospitals against negligence claims, litigation costs can have a serious impact on patient care.

The problems are not confined to the United Kingdom. The United States has experienced recurrent malpractice crises for two decades and similar trends have been found in Europe and Australia. Although this study is set in the United Kingdom, its themes and findings are relevant to all those others concerned with litigation and the management of risk in clinical settings.

There is potential for a much higher level of litigation than currently experienced. Litigation is a relatively infrequent response to an adverse event - an occasion on which a patient is unintentionally harmed by treatment. In the United States, the Harvard medical practice study ${ }^{23}$ found that the rate of negligent adverse events was eight times greater than the number of claims, and 14 times greater than the number of paid claims. Whether or not litigation is involved, adverse events have serious consequences with $21 \%$ involving a death or long term disability. ${ }^{23}$ Patients may have increased pain and disability and may experience psychological trauma from the incident and subsequent litigation. ${ }^{45}$ Staff may be distressed both by the original incident $^{6-8}$ and by the process of litigation. ${ }^{9-11}$

Attempts to control litigation have generally concentrated on the efficient handling of claims or changes to the system of compensation. ${ }^{12-14}$ Improvements are being made to the legal process and some cases are settled more efficiently. ${ }^{15}$ The Wolff enquiry into improving legal processes in the United Kingdom promises further reforms including the possibility of a fast track process for smaller claims. This is intended to benefit both plaintiffs and defendants. However, legal and financial measures alone are insufficient. American risk management programmes ${ }^{16}$ incorporate systems for identifying and reviewing adverse events to consider underlying clinical problems and reduce risk to patients. ${ }^{17-19}$ Similar to American insurance groups, the Central Negligence Scheme for Trusts is offering discounted premiums to hospitals that have an effective risk management programme in place.

Risk management is relatively new in the United Kingdom, although many elements of it are already practised by clinicians and man- 
agers. ${ }^{2021}$ It is only recently that risk managers have been appointed, and protocols for managing clinical risk are in their infancy. It is not yet clear what form risk management in the United Kingdom should take. The primary purpose of this survey was to assess the impact of litigation on senior clinicians and to establish their views on methods of reducing litigation and adverse events. The findings can be used to guide the development of risk management by finding what measures would find support among senior clinicians.

\section{Method}

SURVEY METHOD

A questionnaire was sent to all 820 consultants and 191 senior registrars in the acute specialties in the North Thames (West) Region. A personalised letter assured participants of anonymity and offered the opportunity to telephone the authors to discuss the study. An opt out form invited non-participants to express their reasons for not taking part. Each respondent returned a sheet separately confirming participation in the study to enable us to send a reminder to clinicians who had not responded within two months. There was an initial response rate of over $65 \%$ after which a reminder was sent to non-respondents.

\section{QUESTIONNAIRE DESIGN (APPENDIX)}

The questionnaire covered the following topics:

(1) Characteristics of respondents - Basic demographic information consisted of grade, age, sex, years since qualification.

(2) Experience of litigation - The respondent was asked whether they had ever been involved in litigation. Those who answered yes were asked if an award had been made and whether the case had reached court. The frequency or date of litigation was not asked for as this might make identification possible.

(3) Perceived causes of adverse events Respondents indicated their agreement or disagreement with a series of 12 statements derived from publications ${ }^{15}{ }^{172-24}$ on a five point scale from 1 (strongly disagree) to 5 (strongly agree).

(4) Clinical and personal effects of litigation respondents rated six statements concerning the effects of litigation on clinical practice and 10 effects of litigation on doctors personally where relevant.

(5) Clinicians' recommendations for action four open questions were asked about the action that should be taken to: $(a)$ reduce adverse events, $(b)$ reduce litigation, $(c)$ assist staff, and (d) assist patients involved in litigation.

Before the main study, the questionnaire was submitted for comment to a small group of senior clinicians and was successively revised. After this it was piloted on 10 further clinicians.

ANALYSIS

The results were summarised and analysed according to grade (consultant or senior registrar), whether the clinician had been involved in litigation or not, and by specialty. The $\chi^{2}$ analyses were used to compare categories. As several specialties were too small for statistical analysis $(n<25)$, the individual specialties were divided into two broad groupings; surgical and medical. The surgeries comprised trauma and orthopaedics, obstetrics and gynaecology, general surgery, accident and emergency, and other (cardiothoracic surgery; paediatric surgery; ear, nose, and throat; ophthalmology; plastic surgery; neurosurgery; urology; and oral surgery). The medical specialities included paediatrics, care of the elderly, general medicine, and other (endocrinology; oncology; cardiology; gastrology; thoracic and respiratory medicine; nephrology; genitourinary medicine; dermatology; rheumatology; neurological medicine; and audiological medicine). Responses to the personal effects of litigation only apply to those who had experience of litigation.

The answers to the four open questions were coded according to common themes arising from the responses. Sixty topics were originally identified and similar topic areas were then summarised into 27 broad themes (tables 1 and 2). For example, reducing hours and reducing workload were condensed to "workload or staff ratio"; comments about locums, temporary staff, and overseas doctors were grouped under "transient staff".

\section{Results}

CHARACTERISTICS OF RESPONDENTS

The overall response rate was $76 \%$, made up of $646(79 \%)$ consultants and $123(64 \%)$ senior registrars who replied immediately, and others who did so after a reminder letter. The mean (SD, range) age was $45(8.4,28-67)$, and they had been qualified for a mean of 19 years: 585 (76\%) were men.

\section{EXPERIENCE OF LITIGATION}

Altogether, 252 (39\%) consultants and 36 (29\%) senior registrars had been involved in litigation at some point in their career $(37 \%$ overall). The rates of litigation varied considerably between specialties (fig 1) with 213 (49\%) of clinicians in the surgical specialties having experienced litigation compared with 76 $(23 \%)$ in the medical specialties $\left(\chi^{2} 53.7\right.$, $\mathrm{P}<0.001$, fig 1). Not surprisingly, the likelihood of ever having been involved in litigation increased with years of experience; $28 \%(19 / 67)$ in the first 10 years since qualification, $36 \%$ of those with 11 to 20 years experience (113/312), and $39 \%$ of those with over 20 years experience (144/371).

Of the 288 doctors who had been involved in litigation, $80(28 \%)$ were involved in a case in progress or had not heard the outcome. Of the 208 settled cases, $115(55 \%)$ had had an award made against them in at least one case and 27 $(13 \%)$ had appeared in court.

\section{PERCEIVED CAUSES OF ADVERSE EVENTS}

The most striking finding was the prominence given to communication. Problems were perceived to occur in communication between staff members, with staff and patients, and in written communication in the form of poor 


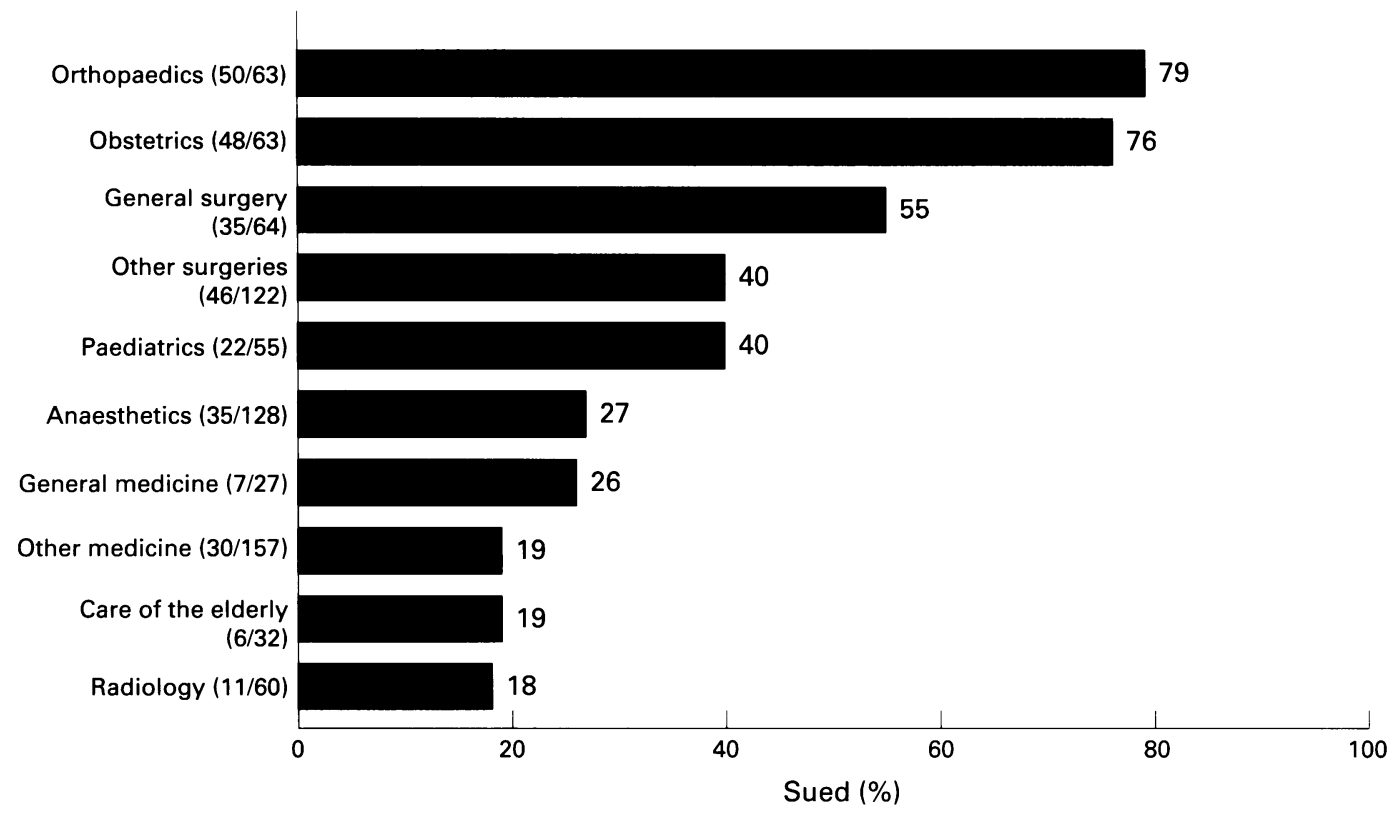

Figure 1 Percentage of doctors sued in each specialty.

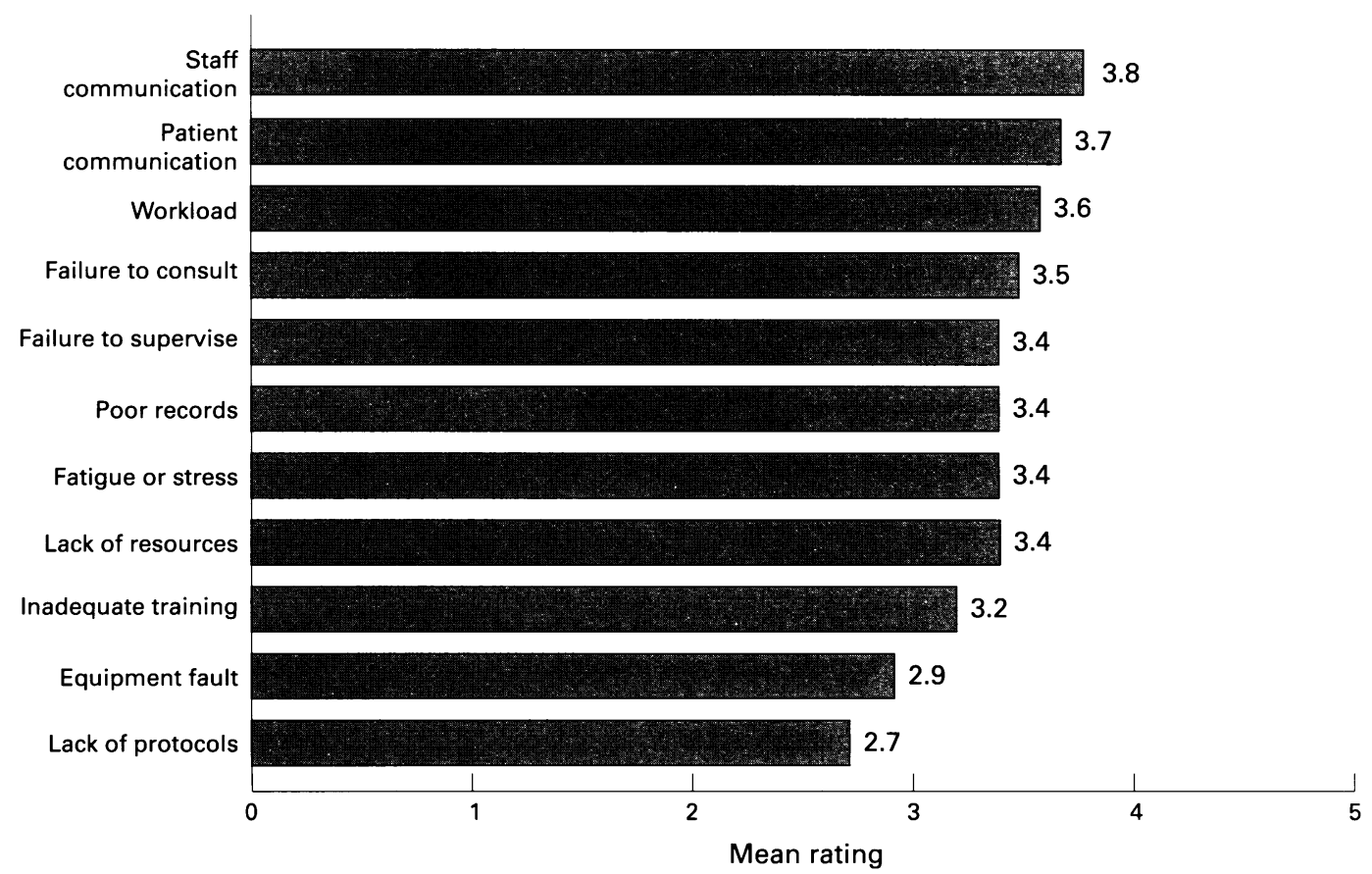

Figure 2 Perceived causes of adverse events.

record keeping (fig 2). Communication problems are also implied in juniors not seeking supervision and in seniors inadequately supervising. There was no difference in views between specialties, between grades, or between those who had experienced litigation or not.

EFFECTS ON CLINICAL PRACTICE

Litigation or the threat of litigation was thought by most respondents to have an impact on clinical practice (fig 3), although this was not necessarily detrimental. There was a high level of agreement between grades which was irrespective of whether litigation had been experienced or not.

Most considered that the threat of litigation has led to attempts to improve communication with patients and staff and to keep better records. Overinvestigation was not generally thought to be a consequence of litigation and only a few responded by avoiding certain procedures or staff members. Avoidance of procedures and avoidance of staff was reported to be more common among those in surgical specialties (30\% and $22 \%$ ) than those in medical specialties $(20 \%$ and $10 \%)\left(\chi^{2} 10.52\right.$, $\mathrm{P}<0.001$ and $\chi^{2} 11.09, \mathrm{P}<0.001$, respectively).

EMOTIONAL IMPACT OF LITIGATION ON DOCTORS The impact of litigation on those with direct experience of it (288) was considerable. Anger, distress, and feeling personally attacked were common (fig 4). There was a tendency for doctors in medical specialties to report strong feelings more often than surgeons $(44 \% v$ $\left.31 \% ; \chi^{2} 3.85, \mathrm{P}<0.01\right)$. Of those who were or had been involved in litigation $56(19 \%)$ had considered giving up medicine altogether. There were no obvious differences in response 


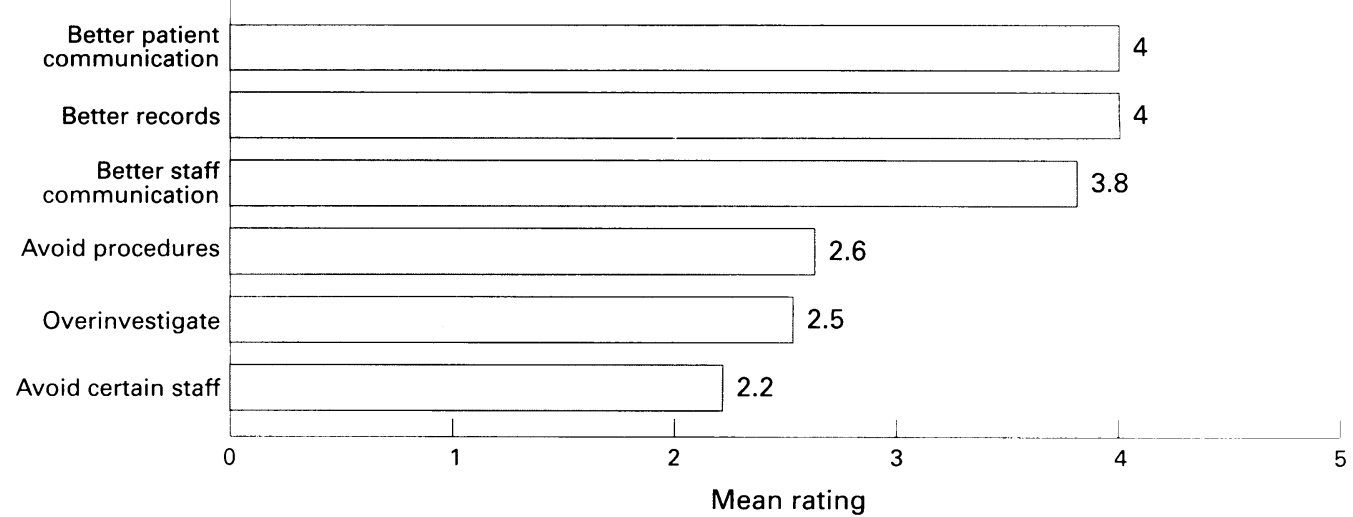

Figure 3 Effects of litigation on subsequent clinical practice.

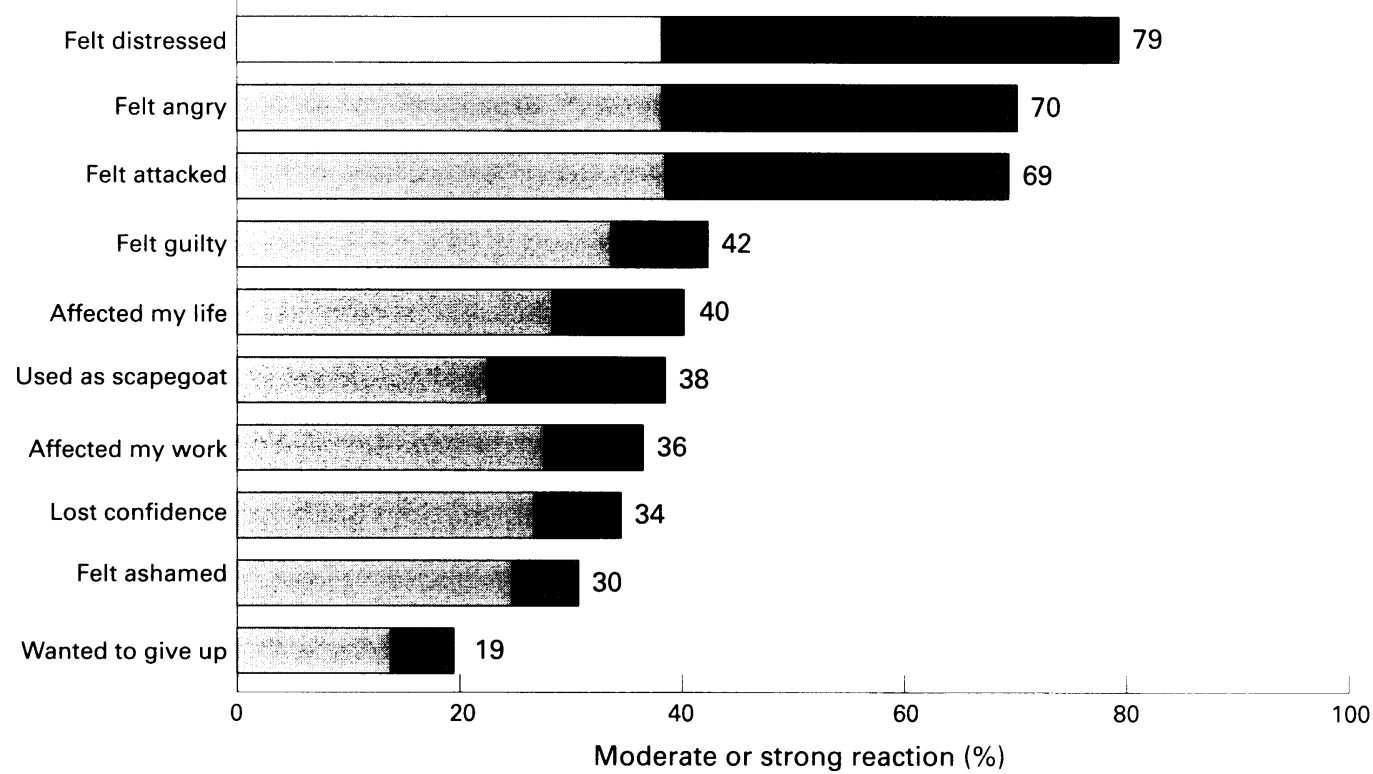

Figure 4 Personal effects of litigation. (Moderate reactions are in light shading, strong reactions in dark.)

between grades, if an award had been made, or if a court appearance was involved.

REDUCING ADVERSE EVENTS

The main themes for reducing adverse events were similar for all grades and specialties. Key areas (table 1) were improving supervision of juniors, controlling workload and staffing levels, and increased use of protocols. Training in clinical techniques and communication skills were recommended. Breakdown in communication between staff members was often mentioned. Transient staff, such as locums, overseas doctors, and inexperienced temporary staff made teamwork difficult. Unavailable clinical information in records was regarded both as a cause of accidents and as an obstacle to defending litigation. Training in record keeping was requested together with the use of specialised clerical staff to keep records to allow doctors more clinical contact time. Limited staff and inadequate equipment were constantly mentioned as contributing to poor quality of care.

REDUCING LITIGATION

Many clinicians considered that an important step in reducing litigation was to educate patients about the known risks and effects of treatment to promote more realistic expectations from medicine (table 1). Written information was strongly recommended for people with English as a second language or with communication difficulties. Dealing sensitively with an injured or distressed patient was stated to be crucial. Senior registrars stressed that consultants needed to be involved as soon as possible after an adverse event. Some doctors remarked that they felt torn between their own wish for an open approach and what they perceived to be their defence societies' directives. There was criticism of the lack of formal training in communication skills. Training was requested for all grades, especially in dealing sensitively with dissatisfied, angry, or distressed patients.

HELPING PATIENTS INVOLVED IN LITIGATION Many responses focused on staff views of patients harmed by their treatment (table 2). The need to maintain a compassionate attitude and provide clear, open, and speedy explanations were stressed. Willingness to accept blame and apologise where appropriate were thought to reduce the likelihood of litigation.

Counselling for patients was recommended. Offering further medical treatment was 
Table 1 Clinicians'views on reducing adverse events and litigation

\begin{tabular}{ll}
\hline Reducing adverse events (n(\%)): & \\
Lower workload or more staff & $245(32)$ \\
Increased supervision of junior staff & $243(32)$ \\
Increased use of protocols & $194(25)$ \\
Update training and techniques & $176(23)$ \\
Training in communication skills & $160(21)$ \\
Less use of transient staff & $125(6)$ \\
Improved equipment & $115(15)$ \\
Reducing litigation (n(\%)): & $338(44)$ \\
Training in communication with patients & $227(30)$ \\
Explain risks before treatment & $225(29)$ \\
Open explanations after incidents & $133(17)$ \\
Increase patient time with consultants & $55(7)$ \\
Training in record keeping & $47(6)$ \\
Improve protocols & $42(5)$ \\
No fault compensation & $40(5)$ \\
Update techniques &
\end{tabular}

The percentages do not total 100 as many doctors made several suggestions.

thought to be important for maintaining hospital trusts and for repairing the doctor-patient relation, and it was appreciated that some patients might prefer a second opinion or change of doctor or hospital. Rectifying problems within the present legal system, faster alternative systems of compensation, and no fault compensation were suggested by some but were not seen as the most pressing need. A few doctors discussed reducing levels of compensation or reducing access to legal aid.

HELPING STAFF INVOLVED IN LITIGATION The psychological effects on staff (table 2) were often referred to and support from friends, colleagues, management, and outside professionals was seen as important. There were embittered and angry comments about the lack of personal support from managers, with descriptions of unfair criticism, judgement, and witch hunting. Management was criticised for a lack of awareness of the effect of litigation on doctors and for failing to consider doctors' needs. Many thought that managers should take a more active interest in defending cases and supporting the staff concerned.

Support groups and legal advice within the hospital system were often proposed, both as an information resource and for moral support. Over a quarter of doctors suggested the formal provision of a counselling service and nominated mentors to whom they could refer. Medicolegal advice and training in how to avoid and deal with complaints and litigation were requested together with support and guidance for doctors involved in litigation. A few specifically mentioned risk management training.

Table 2 Clinicians'views on helping patients and staff

\begin{tabular}{ll}
\hline Helping patients injured during treatment $(\mathrm{n}(\%)):$ & \\
Improve communication & $403(52)$ \\
Offer further treatment & $161(21)$ \\
No fault compensation & $120(16)$ \\
Caring approach by staff & $82(11)$ \\
Counselling for patients & $59(8)$ \\
Changes to legal system & $42(5)$ \\
Senior involvement & $37(5)$ \\
Assisting staff involved in adverse events and & \\
$\quad$ litigation (n(\%)): & \\
Counselling for staff & $225(29)$ \\
Support form management & $190(25)$ \\
Support form colleagues & $188(24)$ \\
Legal advice, defence & $166(22)$ \\
Training & $41(5)$ \\
\end{tabular}

\section{Discussion}

Over a third of our sample of senior clinicians had been involved in litigation with the highest risk specialties being orthopaedic surgeons and obstetricians (over $70 \%$ who had had experience of litigation). Litigation is described by doctors as a distressing and disturbing experience. During the litigation process staff often feel isolated from colleagues and unsupported by management. At times the strain is severe; there were more recommendations for counselling for staff involved in litigation than for patients. Although defensive medicine does not seem common, low morale from litigation is evident.

The principal suggestions for reducing litigation and adverse events are the training and supervision of junior staff, reducing workload, improving the standard of equipment, the use of protocols, and most important of all, communication. Clearly some of these have financial implications and may need to be resolved at trust board level; adequate equipment and staffing are a necessary precondition of running a safe and effective unit. Many safety issues, however, concern the internal organisation of units and, in particular, the communication and relations between different professions, specialties, and grades of staff. Although traditional audit topics have generally focused on specific clinical practices, they should be extended to include reviews of communication pathways and practices of supervision. Risk management as one piece of the quality jigsaw ${ }^{25}$ will hopefully evolve in a way that encourages close collaboration with clinical audit. Few other quality initiatives focus directly on the most serious incidents, and yet their analyses may be one of the most effective ways of uncovering broader organisational problems that may in turn become the targets of systematic audits. ${ }^{26}{ }^{27}$

Communication between staff and patients was often highlighted. Over $50 \%$ of the clinicians mentioned poor communication as a factor in contributing to errors or litigation, a finding which accords with recent research on the reasons patients take legal action. ${ }^{5}$ Studies in the United States also suggest that it is poor communication, rather than obviously deficient care, that most clearly distinguishes clinicians with a history of malpractice litigation. ${ }^{26} 27$ Clearly more emphasis must be put on communication training throughout the medical career, at present an aspect still treated as secondary in undergraduate and postgraduate development. $^{28}$

A systematic approach to risk management across an entire hospital has yet to be developed, at least within the United Kingdom National Health Service, but risk management protocols have been developed in some specialties. Beard and O'Connor described a review of risk in an obstetric unit $^{29}$ that led to a risk management protocol involving new policies on induction of new staff, the use of locums, communication between doctors and midwives, consent to treatment, and standards of record keeping. A trustwide risk management policy could usefully adapt such an approach in an internal review of all high risk areas. 
There are several areas highlighted in this survey which could be usefully and effectively considered by risk managers directly and which would be well received by clinical staff. A risk management team can provide legal advice and information about medical negligence law, the way the legal process operates and the realities of being in court, and keep the clinician informed on any progress in an impending case. The next priority should be the provision of an effective support scheme, probably with senior clinical staff as mentors, for those involved in serious claims. It may be useful to follow one hospital trust which employs recently retired consultants as mentors. A link with a psychiatrist or psychologist, perhaps outside the hospital trust, might also be useful when the strain is severe or prolonged, as occurs when a member of staff feels responsible for a serious injury or death.

A third area that risk managers need to consider is the provision of training in communication skills for coping with, and helping dissatisfied, distressed, or injured patients and their relatives. Some litigation and many formal complaints could probably be avoided by a sensitive initial response to complaints or incidents in which patients have been harmed. When formal complaints or litigation have been initiated, it may still be helpful for the risk management team to negotiate a settlement which does not involve a protracted legal process with all the attendant expense and strain on both patients and staff.

Risk managers are in a strong position to identify hospital wide training needs. Attempts to improve communication, record keeping, technological awareness, and other areas that potentially contribute to risk can only realistically happen in a structured teaching situation. Training in how to effectively analyse and learn from mistakes is crucial. The blame culture is still very apparent and the focus must move away from individual people and on to a systems approach of examining why events took place, ${ }^{830}$ and improvement must be produced. ${ }^{31}$ It is only once the root causes of weaknesses within the system are identified and resolved that quality of care will improve.

Effective risk management requires a collaborative approach between clinicians and management with a basic strategy agreed by the hospital trust board. Many of the suggestions made - such as early intervention with injured patients - are only feasible if backed by a management policy that encourages doctors to be open with patients about mistakes that have been made. Some doctors are still torn between their own desire for a more open stance and the more cautious approach that they perceive to be demanded, rightly or wrongly, by managers and the defence societies. In the long term a fundamental shift of attitude is needed at all levels, towards a greater openness with injured patients and a move away from the blame culture that can easily dominate serious incident enquiries and even routine audit meetings.
The process of medical litigation is distressing for all concerned. Patients, who may have been traumatised by a mistake in their health care, face an uphill court battle at a time when they may also have severe health difficulties. Staff may find the situation disturbing and may wish to distance themselves from the patients. By considering the reasons why things can go wrong in medicine so that the risks are minimised and the safety of health provision is improved, patients and staff will benefit from a quality of service they both desire.

1 May L. Litigation. NHS Magazine 1996;4:17-9.

2 Hiatt HH, Barnes BA, Brennan TA, Laird NM, Lawther AG, Leape LL, et al. A study of medical injury and medical malpractice: an overview. $N$ Engl f Med 1989;321:480 4.

3 Leape LL, Brennan TA, Laird N, Lawthers AG, Hiatt H. Adverse events and negligence in hospitalized patients. Iatrogenics 1991;1:17-21.

4 Vincent CA, Pincus T, Scurr JH. Patients' experience of surgical accidents. Quality in Health Care 1993;2:77-82.

5 Vincent C, Young M, Phillips A. A study of patients and Vincent C, Young M, Phillips A. A study of patients
relatives taking legal action. Lancet 1994;343:1609-13.

6 Hilfiker D. Facing our mistakes. $N$ Engl $f$ Med 1984; 310,118-22.

7 Firth-Cozens J. Stress, psychological problems and clinical performance. In: Vincent C, Ennis M, Audley R, eds. Medical accidents. Oxford: Oxford University Press, 1993.

8 Vincent C, Bark P. Accident investigation: discovering why things go wrong. In: C Vincent, ed. Clinical risk management. London: BMJ, 1995.

9 Charles SC. A different view of malpractice. Chicago Medicine 1984;87:848-50.

10 Charles SC, Wilbert JW, Franke KJ. Sued and non-sued physicians' self-reported reactions to malpractice litigaphysicians' self-reported reactions to
tion. Am $₹$ Psychiatry 1985;142:437-40.

11 Ennis M, Grudzinskas JG. The effects of accidents and litigation on doctors. In: Vincent C, Ennis M, Audley R, eds Medical accidents. Oxford: Oxford University Press, 1993

12 Brahams D. No fault compensation based on patient insurance. Lancet 1987:698.

13 Capstick JB, Edwards PJ. Trends in obstetric malpractice claims. Lancet 1990;336:931-2.

14 Fenn P. Compensation for medical injury: a review of policy options. In: Vincent C, Ennis M, Audley R, eds. Medical accidents. Oxford: Oxford University Press, 1993.

15 Clements RV. Obstetric litigation. In: Advances in obstetrics and gynaecology. Oxford: The Medicine Group, 1992.

16 Mills DH. Clinical risk management: experiences from the United States. In: Vincent C, ed. Clinical risk management. London: BMJ, 1995.

17 Ennis M, Vincent CA. Obstetric accidents: a review of 64 cases. $B M \mathcal{F}$ 1990;300:1365-7.

18 Clements RV. Litigation in obstetrics and gynaecology. $\mathcal{f}$ Obstet Gynaecol 1991;98:423-6.

19 Cooper JB, Newbower RS, Kitz RJ. An analysis of major errors and equipment failures in anaesthesia management: considerations for prevention and detection. Anaesthesiology 1984;60:34-42.

20 Dingwall R, Fenn P. Is risk management necessary? International fournal of Risk and Safety in Medicine $1991 ; 2: 91-106$

21 NHS Management Executive. Risk management in the NHS. London: Department of Health, 1993.

22 Bognor MS, ed. Human error in medicine. Hillsdale, New Jersey: Erlbaum, 1994.

23 Vincent C, Ennis M, Audley RJ, eds. Medical accidents. Oxford: Oxford University Press, 1993.

24 Ennis M, Clark A, Grudzinskas JG. Change in obstetric practice in response to fear of litigation in the British Isles. Lancet 1991;338:616-8.

25 Vincent C, Moss F. Clinical risk management: one piece of the quality jigsaw. Quality in Health Care 1995;4:73-4.

26 Entman SS, Glass CA, Hickson GB, Githens PB, Whetten Goldstein K, Sloan FA. The relationship between malpractice claims history and subsequent obstetric care. FAMA 1994;272:1588-91.

27 Hickson GB, Clayton EW, Entman SS, Miller CS, Githens PB, Whetten-Goldstein K, Sloan FA. Obstetricians' prior malpractice experience and patients' satisfaction with care. FAMA 1994;272:1583-7.

28 McManus IC, Vincent CA, Thom S, Kidd J. Teaching communication skills to clinical students. $B M \mathcal{F}^{1993}$ 306:1322-7.

29 Beard R, O'Connor A. Implementation of audit and risk management - a protocol. In: C Vincent, ed. Clinical rish management, London: BMJ, 1995.

30 Reason JT. The human factor in medical accidents. In: CA Vincent, M Ennis, RJ Audley, eds. Medical accidents. Oxford: Oxford University Press, 1993.

31 Berwick DM. A primer on leading the improvement of systems. BMF 1996;312:619-22. 


\section{Appendix: Litigation in the North (West) Thames Region}

GENERAL INFORMATION

1 Your grade

2 Your specialty

3 How long was it since you qualified? (please ring one)

0 to 2 years 2 to 5 years 5 to 10 years 10 to 20 years over 20 years

4 Age

5 Sex: male / female

THE CAUSES OF ADVERSE EVENTS

6 The following are potential causes of incidents in which a patient is harmed by an aspect of medical treatment. Please rate all the statements according to your view of how far you agree with them as relevant to causing accidents in your specialty.

Please give the causes you feel are the most important (whether or not listed above).

\begin{tabular}{|c|c|c|c|c|c|}
\hline & $\begin{array}{l}\text { Strongly } \\
\text { disagree }\end{array}$ & Disagree & Neutral & Agree & $\begin{array}{l}\text { Strongly } \\
\text { agree }\end{array}$ \\
\hline (a) Equipment fault & 1 & 2 & 3 & 4 & 5 \\
\hline (b) Excessive workload & 1 & 2 & 3 & 4 & 5 \\
\hline \multicolumn{6}{|l|}{ (c) Failure of communication between staff (for example, during } \\
\hline & 1 & 2 & 3 & 4 & 5 \\
\hline (d) Failure of communication with the patient & 1 & 2 & 3 & 4 & 5 \\
\hline (e) Failure of junior staff to consult with senior colleagues & 1 & 2 & 3 & 4 & 5 \\
\hline (f) Failure of senior staff to supervise junior staff adequately & 1 & 2 & 3 & 4 & 5 \\
\hline (g) Inadequate education or training & 1 & 2 & 3 & 4 & 5 \\
\hline (h) Incomplete/poor records or notes & 1 & 2 & 3 & 4 & 5 \\
\hline (i) Lack of clear guidelines or protocol & 1 & 2 & 3 & 4 & 5 \\
\hline (j) Lack of resources (staff or equipment) & 1 & 2 & 3 & 4 & 5 \\
\hline \multicolumn{6}{|l|}{ (k) Staff undertaking procedures for which they lack the } \\
\hline appropriate skills & 1 & 2 & 3 & 4 & 5 \\
\hline (1) Fatigue or stress & 1 & 2 & 3 & 4 & 5 \\
\hline
\end{tabular}

THE EFFECT ON YOUR CLINICAL PRACTICE

Please rate the following whether or not you have actually been involved in legal action.

7 Litigation or the threat of litigation has led me to make the following changes in the past few years:

Please say what the most important change (if any) has been in your own practice.

\begin{tabular}{|c|c|c|c|c|c|}
\hline & $\begin{array}{l}\text { Strongly } \\
\text { disagree }\end{array}$ & Disagree & Neutral & Agree & $\begin{array}{l}\text { Strongly } \\
\text { agree }\end{array}$ \\
\hline (a) I try to communicate better with staff & 1 & 2 & 3 & 4 & 5 \\
\hline (b) I try to communicate better with patients & 1 & 2 & 3 & 4 & 5 \\
\hline (c) I keep better records & 1 & 2 & 3 & 4 & 5 \\
\hline (d) I tend to overinvestigate & 1 & 2 & 3 & 4 & 5 \\
\hline (e) I am reluctant to use certain procedures & 1 & 2 & 3 & 4 & 5 \\
\hline (f) I am reluctant to work with certain staff & 1 & 2 & 3 & 4 & 5 \\
\hline
\end{tabular}

THE EFFECT OF LITIGATION ON YOU PERSONALLY

8 Have you been involved in litigation yourself? Yes No

If NO please go to question 14 .

9 Was an award made? Yes No Case in progress

10 Did you have to appear in court? Yes No Case in progress

11 How did being involved in litigation affect you? Please rate all the statements.

12 What help would you personally have liked from colleagues or management?

\begin{tabular}{|c|c|c|c|c|c|}
\hline & $\begin{array}{l}\text { Strongly } \\
\text { disagree }\end{array}$ & Disagree & Neutral & Agree & $\begin{array}{l}\text { Strongly } \\
\text { agree }\end{array}$ \\
\hline (a) I felt ashamed & 1 & 2 & 3 & 4 & 5 \\
\hline (b) I felt distressed & 1 & 2 & 3 & 4 & 5 \\
\hline (c) I felt guilty & 1 & 2 & 3 & 4 & 5 \\
\hline (d) I felt angry & 1 & 2 & 3 & 4 & 5 \\
\hline (e) I felt personally attacked & 1 & 2 & 3 & 4 & 5 \\
\hline (f) I felt I was a scapegoat for others' errors & 1 & 2 & 3 & 4 & 5 \\
\hline (g) I felt like giving up medicine & 1 & 2 & 3 & 4 & 5 \\
\hline (h) I lost confidence & 1 & 2 & 3 & 4 & 5 \\
\hline (i) My personal life was adversely affected & 1 & 2 & 3 & 4 & 5 \\
\hline (j) My work was adversely affected & 1 & 2 & 3 & 4 & 5 \\
\hline
\end{tabular}

13 Please give your views on what action could be taken:
(a) to reduce adverse events and litigation?
(b) to assist staff involved in litigation
(c) to help patients injured during treatment?

Thank you for taking part in the study 